\title{
COLOR STABILITY OF CERAMIC OCCLUSAL VENEER WITH DIFFERENT TRANSLUCENCY, DESIGNS AND RESIN CEMENT CURING MODES USING “ACCELERATED ARTIFICIAL AGING”
}

\author{
Adel A. El Badawy *, Mohammed H. Abd El Aziz* and Elsayed A. Omar*
}

\begin{abstract}
Statement of problem: Clinically, Occlusal veneers is thin resin bonded restoration making color change liable to occur.

Purpose: The aim of the present study was directed to evaluate occlusal veneer color stability with different ceramic materials translucency, axial wall convergence angle and resin cement curing mode systems using "accelerated Artificial Aging".

Materials and Methods: Eighty maxillary first molars were carefully selected and were divided into two main divisions (12 and 22 degree of convergence angle) $(\mathrm{n}=40)$, then each main division was divided into two groups $(n=20)$ according to ceramic translucency (high and low translucency [HT and LT], finally, each group was subdivided into two subgroups $(n=10)$ according to the type of used resin cement (light and dual cure). Occlusal surfaces were reduced leaving 5 millimeters. Shoulder finish line was made with $1 \mathrm{~mm}$ thickness and $1.5 \mathrm{~mm}$ height. The occlusal surface was made using the Cerec scanner software's design tools. The occlusal veneer specimens were cemented using light and dual cured resin cement. The initial color measurements were taken followed by accelerated aging process and finally, second color measurement was taken.
\end{abstract}

Results: The highest mean value of color variation $(\Delta \mathrm{E})$ was recorded at $12^{\circ}$ convergence angle in the high translucent (HT) samples that have been cemented by light cured resin cement $(2.01 \pm 0.16)$, while the lowest mean value of color variation $(\Delta \mathrm{E})$ was recorded at $22^{\circ}$ convergence angle in the low translucent (LT) samples that have been cemented by dual cured resin cement $(1.28 \pm 0.11)$.

Conclusions: Color stability of occlusal veneer is apparently affected by ceramic translucency, degree of preparation convergence angle and curing mode of resin cement.

\footnotetext{
* Assistant professor of Crown \& Bridge, Faculty of Dentistry, Al Azhar University
} 


\section{INTRODUCTION}

In case of severe teeth wear, restorative treatment is required to protect weak tooth surfaces and reestablish reasonable appearance and function. [1] Considerable research exist to support the use of composite restoration to restore worn teeth. ${ }^{[2]}$ Occlusal veneer have been suggested as a more conservative treatment modality. Introducing the adhesive restorations with their ability to simulate the natural appearance of both enamel and dentin led to diminishing the need for intra-radicular preparation and unreasonable reduction of remaining tooth structures ${ }^{[3]}$. All ceramic restorations have desired esthetics and durability, recent improvements in CAD/CAM materials and technology presented a new possibility for restoration of severely worn dentition. Color stability for both restorative materials and resin cement play an important role for restoration longevity. ${ }^{[4,5]}$

There is a range of authors opinions about the effect of polymerization mode of resin cements on the color stability, many specialists favor the light-cured luting cements, ${ }^{[6,7]}$ on the other hand, some authors proved that, dual cured resin cement exhibited greater color stability than light cured cement. ${ }^{[8,9]}$ Accelerated artificial aging is a widely used technique for assessing the durability of optical properties for many restorative materials. This method mimics the clinical considerations as far as possible ${ }^{[10]}$, by which, the material is subjected to different conditions, such as continuous alterations in humidity, temperature and UV light, many different restorative materials and restorations can be evaluated by this technique, especially allceramic restorations and resin cements ${ }^{[6,7]}$.

The aim of the present study was directed to evaluate occlusal veneer color stability with different ceramic materials translucency, axial wall convergence angle and resin cement curing mode systems using "accelerated Artificial Aging”.

\section{MATERIALS AND METHODS}

Eighty maxillary first molars were selected and were examined under $4 \mathrm{x}$ magnification loops for any cracks, caries or old restorations. Specimens were randomly divided into two main divisions according to degree of convergence angle (12 and 22) ${ }^{[11-14]}(n=40)$, then each group was subdivided into two groups $(n=20)$ according to the ceramic type (lithium di silicate high translucency [HT] and low translucency [LT]) and finally, each group was subdivided into two subgroups $(\mathrm{n}=10)$ according to the type of used resin cement (light cure and dual cure) forming eight subgroups as seen in the following table (1)

Table (1): Classification of tested samples

\begin{tabular}{|c|c|c|c|c|c|}
\hline $\begin{array}{c}\text { Convergence } \\
\text { angle }\end{array}$ & Ceramic & \multicolumn{2}{|c|}{$\mathrm{N}$} & Sub groups & Type of resin cement \\
\hline \multirow{4}{*}{$12^{\circ}$} & \multirow{2}{*}{ HT } & \multirow{2}{*}{20} & 10 & (1) & Dual cure \\
\hline & & & 10 & (2) & Light cure \\
\hline & \multirow{2}{*}{ LT } & \multirow{2}{*}{20} & 10 & (3) & Dual cure \\
\hline & & & 10 & (4) & Light cure \\
\hline \multirow{4}{*}{$22^{\circ}$} & \multirow{2}{*}{ HT } & \multirow{2}{*}{20} & 10 & (5) & Dual cure \\
\hline & & & 10 & (6) & Light cure \\
\hline & \multirow{2}{*}{ LT } & \multirow{2}{*}{20} & 10 & (7) & Dual cure \\
\hline & & & 10 & (8) & Light cure \\
\hline
\end{tabular}


Using micro saw with a diamond disc, occlusal surfaces of all teeth were reduced and flattened [15] leaving 5 millimeters occlusal to the cemento - enamel junction. ${ }^{[16,17]}$ After cutting, teeth were examined for any cracks or pulp exposure. Any cracked tooth was discarded and replaced by intact one. Circumferential shoulder finish line was made with $1 \mathrm{~mm}$ thickness and $1.5 \mathrm{~mm}$ height ${ }^{[18,19]}$ using lab diamond stone with flat tip. Axial wall convergence angles were made $\left(12^{\circ}\right.$ and $\left.22^{\circ}\right)$ for group (A) and (B) (40 specimens foe each) as shown in figure (1).

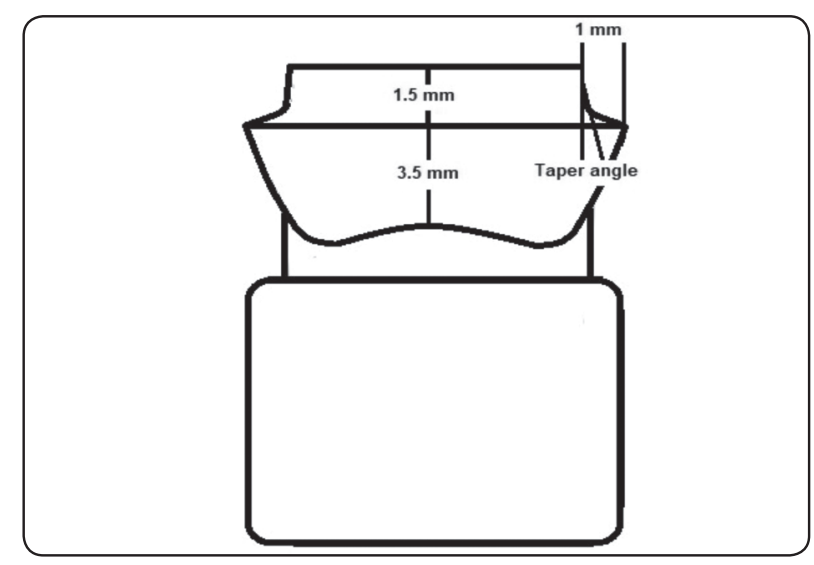

Fig. (1): Diagram of prepared tooth dimensions.

The prepared teeth were then kept in a path of distilled water for 24 hours before processing and cementation of the final occlusal veneer restorations. The occlusal surface was made using the Cerec scanner software's design tools (in Eos Blue scanner) set in a Mode, with a thickness of 1.8 $\mathrm{mm}$ (from the reduced occlusal surface to the level of occlusal plane. The design of the restoration was attained by the sole use of the "position" tools. The restoration design was accomplished by Cerec in Lab 3D software (version 4.2) and finally by using Cerec MC XL milling unit, 40 IPS e.max CAD (Ivoclar, Liechtenstein) occlusal veneers for each convergence angle (20 for high translucent HT and 20 for low translucent LT) were fabricated. ${ }^{[16,18]}$ Using programat P310 furnace, occlusal veneers were crystalized according to the manufacturer instructions. Finally, all teeth were fixed in self-cure acrylic resin within a plastic ring.

Using IPS hydrofluoric acid 9\% ceramic etching gel (Ivoclar Vivadent), The intaglio surfaces of the restorations were etched, rinsed with water and finally dried. Ceramic primer (Ivoclar Vivadent) was usedd for 60 seconds and finally air dried.

The prepared enamel and dentin surfaces were etched for 15 seconds using phosphoric acid $37.5 \%$ (Ultradent, USA), then rinsed and blot-dried. Resin cements were applied in the intaglio surfaces of the restorations according to the previously classified sub groups (table 3) where dual cure resin cement (Variolink N; Ivoclar Vivadent) were applied in 1, 3, 5 and 7 sub-groups specimens while light cure resin cement (Variolink veneer; Ivoclar Vivadent) were applied to 2, 4, 6 and 8 sub-groups specimens, then, using a specially designed device, a constant vertical pressure was applied on the cemented occlusal veneer. ${ }^{[20]}$ The occlusal veneer specimens were subjected to halogen light device (Smart Lite Max LED, USA) for 120 seconds, then, the specimens with their restorations were stored in distilled water at room temperature for 24 days before testing.

The initial color measurements were taken for all occlusal veneer samples using a spectrophotometer (X-Rite,model: RM 200 QC, Germany), with 99.4\% repeatability, $99.7 \%$ accuracy and geometry $\mathrm{d} / 8^{\circ}$, calculation at standard illumination (D65) (recommended for small samples at close observation), as recommended parameters by CIE (Comission Internationale de L'Éclairage) flat surface of spectrometer's pointer was placed toward the center of the occlusal veneer surface occupying its entire occlusal plane (Acetal polyoxymethylene white, color stable background was used). ${ }^{[21]}$

For artificial aging process, an incubator model (Jeio Tech TEMI 300. Korea) was used. using controlled humidity and 9 UV-B light 
source with radiation of $280 / 320 \mathrm{~nm}$ at for four hours, fluctuant temperatures for 300 hours (equivalent to 1 year of clinical condition). ${ }^{\text {22,24] }}$ Then, second color readouts were taken and the color changes $(\Delta \mathrm{E})$ were calculated using the following formula ${ }^{[25,26]}$ :

\section{$\Delta E\left(L^{*} a^{*} b^{*}\right)=\left[\left(L^{*} 1^{\text {before }}-L^{*} 2^{\text {after }}\right) 2+\right.$ $\left.\left(a^{*} 1-a^{* 2}\right) 2+\left(b^{* 1} 1-b^{* 2}\right) 2\right]^{1 / 2}$.}

where $\Delta \mathrm{E}$ (color change); $\Delta \mathrm{L}$ (lightness alteration), so that the; $\Delta \mathrm{a}$ (axis a) difference; $\Delta \mathrm{b}$ (axis b) difference;

\section{RESULTS}

Computed descriptive statistics were done using statistical-package of social science (SPSS) statistic software (SPSS for windows, version 21.0, SPSS Inc. Chicago). The mean values of $\Delta \mathrm{E}$ were listed in table (2) and compared according to types of ceramic translucency (High and low translucency) IPS e.max cad occlusal veneer, different degrees of convergence angle for two types of resin cement curing mode, using one - way ANOVA test (at $\mathrm{p}<0.05$ ).

For all tested occlusal veneer restorations, the highest mean value of color variation $(\Delta \mathrm{E})$ was recorded at $12^{\circ}$ convergence angle in the high translucent (HT) IPS emax CAD samples that have been cemented by light cured resin cement $(2.01 \pm 0.16)$ (sub group 2), while, the lowest mean value of color variation $(\Delta \mathrm{E})$ was recorded at $22^{\circ}$ convergence angle in the low translucent (LT) IPS emax CAD samples that have been cemented by dual cured resin cement (1.28 \pm 0.11$)$ (sub group 7) ( table 2 and figure 2, 3 and 4).

Multiple comparison statistics of dependent values (Post Hoc analysis) exhibited statistical significant differences between sub groups 1, 2, 5 and 6, also, there is no statistical significant differences between sub groups 3 and 4 from one hand and between sub groups 7 and 8 from other hand (at level of significance $p$ value $<0.05)($ table 3$)$.

Regarding IPS emax CAD translucency, high translucent (HT) IPS emax CAD exhibited higher value of color variation $(\triangle \mathrm{E})$ in relation to low translucent (LT) IPS emax CAD, particularly, when cemented by light cure resin cement at $12^{\circ}$ convergence angle prepared teeth. Regarding geometric relationship of the axial wall, samples with $12^{\circ}$ convergence angle exhibited higher value of color variation $(\Delta \mathrm{E})$ in relation to $22^{\circ}$ convergence angle, particularly, when cemented by light cure resin cement. Finally, regarding to type of polymerization (curing) mode of resin cement, samples luted with light cure resin cement exhibited higher value of color variation $(\Delta \mathrm{E})$ in relation to that luted with dual resin cement, particularly, when used with high translucent (HT) IPS emax CAD at $12^{\circ}$ convergence angle.

TABLE (2): The mean values of $\Delta \mathrm{E}$ for occlusal veneer with two types of ceramic translucency, different degrees of convergence angle and different resin cement curing mode.

\begin{tabular}{|c|c|c|c|c|c|}
\hline \multirow{2}{*}{ Ceramic } & Convergence angle & $\begin{array}{c}\text { Dual cure resin } \\
\text { cement }\end{array}$ & Sub group & $\begin{array}{c}\text { Light cure resin } \\
\text { cement }\end{array}$ & Sub group \\
\hline \multirow{2}{*}{ HT } & ${ }^{\circ} \mathbf{1 2}$ & $0.14 \pm 1.81$ & 1 & $0.16 \pm 2.01$ & 2 \\
\cline { 2 - 6 } & $\circ \mathbf{2 2}$ & $0.11 \pm 1.33$ & 3 & $0.8 \pm 1.35$ & 4 \\
\hline \multirow{2}{*}{ LT } & $\circ \mathbf{1 2}$ & $0.9 \pm 1.44$ & 5 & $0.14 \pm 1.59$ & 6 \\
\hline
\end{tabular}


TABLE (3): Statistical significance for different tested groups

\begin{tabular}{|c|c|c|c|c|c|c|c|c|}
\hline Sub group & 1 & 2 & 3 & 4 & 5 & 6 & 7 & 8 \\
\hline 1 & & 0.00 & 0.00 & 0.00 & 0.00 & 0.00 & 0.00 & 0.00 \\
\hline 2 & 0.00 & & 0.00 & 0.00 & 0.00 & 0.00 & 0.00 & 0.00 \\
\hline 3 & 0.00 & 0.00 & & $0.195 *$ & 0.00 & 0.00 & 0.008 & $0.067 *$ \\
\hline 4 & 0.00 & 0.00 & $0.195 *$ & & 0.00 & 0.00 & 0.001 & 0.008 \\
\hline 5 & 0.00 & 0.00 & 0.00 & 0.00 & & 0.00 & 0.00 & 0.00 \\
\hline 6 & 0.00 & 0.00 & 0.00 & 0.00 & 0.00 & & 0.00 & 0.00 \\
\hline 7 & 0.00 & 0.00 & 0.008 & 0.001 & 0.00 & 0.00 & & $* 0.195$ \\
\hline 8 & 0.00 & 0.00 & $0.067 *$ & 0.008 & 0.00 & 0.00 & $* 0.195$ & \\
\hline
\end{tabular}

* No statistical significant difference at the 0.05 level.

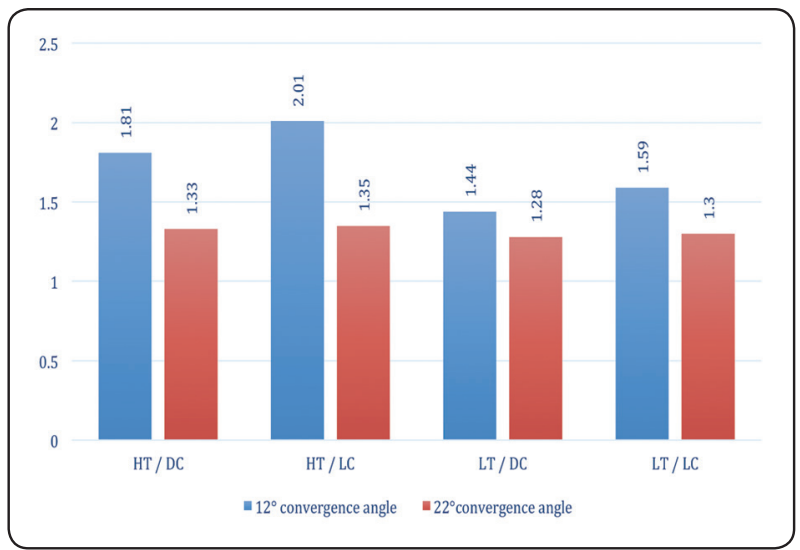

Fig. (2): Mean $\Delta \mathrm{E}$ regarding convergence angle (HT: High translucent ceramic, LT: Low translucent ceramic, DC: Dual cure resin cement, LC: Light cure resin cement

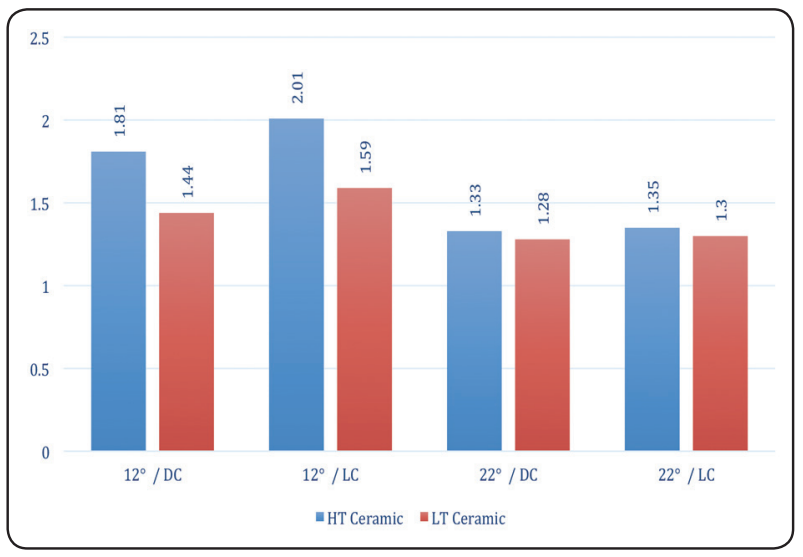

Fig. (3): Mean $\Delta E$ regarding Ceramic translucency (HT: High translucent ceramic, LT: Low translucent ceramic, DC: Dual cure resin cement, LC: Light cure resin cement

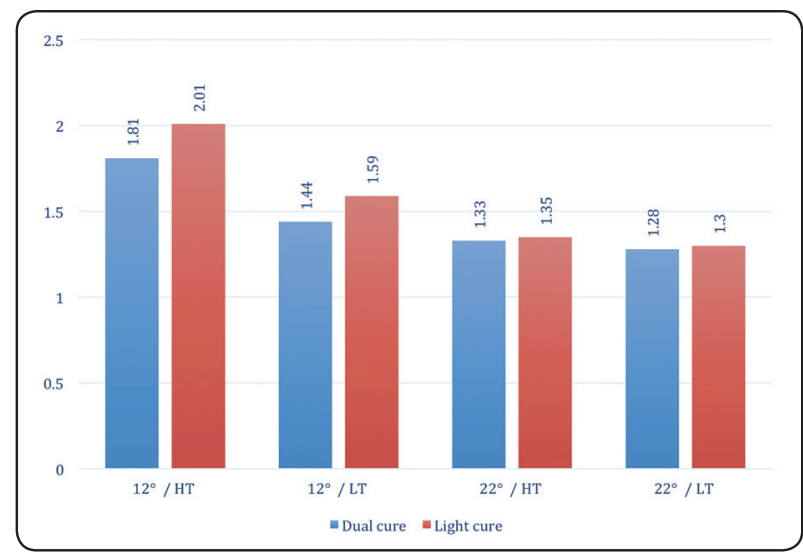

Fig. (4): Mean $\Delta \mathrm{E}$ regarding resin cement curing mode (HT: High translucent ceramic, LT: Low translucent ceramic, DC: Dual cure resin cement, LC: Light cure resin cement

\section{DISCUSSION}

In this study, the parameters used were those of a color system (color space) created by the Commission Internationale de l'Eclairage (CIE). where, $\mathrm{L}^{*}$ parameter is the brightness, $\mathrm{a}^{*}$ is the redgreen chromatic coordinate and $b^{*}$ is the yellowblue chromatic coordinate ${ }^{[27]}$. In addition to that, (CIE) approved the clinical parameter of $(\Delta \mathrm{E})$, where, 0 value, is perfect; 0.5 to 1 , is excellent; 1 to 2 is good; 2 to 3.5 , is clinically acceptable; and $>3.5$, is color mismatch). ${ }^{[28]}$ Thus, $\Delta \mathrm{E}$ values more than 3.5 value is considered clinically unacceptable, 
accordingly, the results of this study were within the range from good to clinically accepted.

In this study, the color stability of occlusal veneers was apparently affected by differences in ceramic translucency, geometric relationship of prepared axial walls as well as type of polymerization (curing) mode of luting resin cements. Cemented high translucent (HT) IPS emax CAD occlusal veneer exhibited higher color change than low translucent (LT), this result is in accordance with other studies which exhibited that, high translucent (HT) IPS emax CAD has high value of transparency parameter (TP) with higher ability for light transmission to the underlying cement layer ${ }^{[29,30]}$. Therefore, ceramics of higher translucency are thought to be less able to mask discoloration of the underlying resin cement than ceramics of lower translucency.

In this study, degree of convergence angle influenced the color parameters evaluated, decreasing the degree of convergence angle led to decreasing in axial ceramic thickness with increasing dimension of occlusal veneer ceramic occlusal table. overall presenting higher $a^{*}, b^{*}$, $\mathrm{L}^{*}$ values, increasing dental ceramic thickness results in increased $\mathrm{L}^{*}$ parameter resulting in darker ceramic. From other hand increasing in axial ceramic thickness with decreasing dimension of occlusal ceramic occlusal table led to decrease in value of transparency parameter (TP) and amount of light transmission to the underlying cement layer [31]

In this study, polymerization(curing) mode of luting resin cement affect apparently in color stability of occlusal veneer regardless types of ceramic translucency and geometric relationship of prepared axial walls, where, $(\Delta \mathrm{E})$ value of dual cure resin cement was lower than that of light cure cement. This is because, dual cure cement contains different amines in its composition, one of them (which is aromatic in its nature and susceptible to degradation) reacts with benzoyl peroxide initiating the chemical polymerization and another type of amine (which is aliphatic and chemically more stable) reacts with camphor quinone for light polymerization, increasing degree of conversion, thus dual cure cement has low degradation leading to more color stability. ${ }^{[32-33]}$

\section{CONLUSION}

Within the limitations of this study, the following were concluded:

1. Color stability of occlusal veneer is apparently affected by ceramic translucency, degree of preparation convergence angle and curing mode of resin cement.

2. The lower ceramic translucency, the higher the color stability for occlusal veneer.

3. The higher degree of convergence angle, the higher the color stability for occlusal veneer.

4. Dual cure luting resin cement for occlusal veneer exhibited more color stability than light cure luting cement.

5. Color differences were within the range from good to clinically accepted

\section{REFERENCES}

1. Lussi A, Hellwig E, Ganss C, Jaeggi T. Buonocore. Memorial Lecture. Dental Erosion. Per Dent 2009; 34:251-262.

2. Redman CD, Hemmings KW, Good JA. The survival and clinical performance of resin-based composite restorations used to treat localized anterior tooth wear. Br Dent J 2003; 194(10):566-572.

3. Stappert CF, Chitmongkolsuk S, Silva NR, Att W, Strub JR. Effect of mouth motion fatigue and thermal cycling on the marginal accuracy of partial coverage restorations made of various dental materials. Dent Mater 2008; 24:1248-1257.

4. Hitz T, Stawarczyk B, Fischer J, Hämmerle CH, Sailer I. Are self-adhesive resin cements a valid alternative to conventional resin cements? A laboratory study of the longterm bond strength. Dent Mater 2012; 28:1183-1190.

5. Turgut S, Bagis B. Colour stability of laminate veneers: an in vitro study. J Dent 2011; 39:57-64. 
6. Archegas LR, Freire A, Vieira S, Caldas DB, Souza EM. Colour stability and opacity of resin cements and flowable composites for ceramic veneer luting after accelerated ageing. J Dent 2011; 39:804-810.

7. Kilinc E, Antonson SA, Hardigan PC, Kesercioglu A. Resin cement color stability and its influence on the final shade of all-ceramics. J Dent 2011; 39:30-36.

8. Garcia LaF, Mundim FM, Pires-de-Souza FeC, Puppin Rontani RM, Consani S. Effect of artificial accelerated aging on the optical properties and monomeric conversion of composites used after expiration date. Gen Dent 2013; 61:1-5.

9. Ghavam M, Amani-Tehran M, Saffarpour M. Effect of accelerated aging on the color and opacity of resin cements. Oper Dent 2010; 35:605-609.

10. Silami F D, Tonani R, Alandia-Román C C, Pires-deSouza F C Influence of Different Types of Resin Luting Agents on Color Stability of Ceramic Laminate Veneers Subjected to Accelerated Artificial Aging. Brazilian Dental Journal.2016; 27(1): 95-100.

11. Corazza PH, Feitosa SA, Souto Borges AL, Bona AD. Influence of convergence angle of tooth preparation on the fracture resistance of Y-TZP-based all-ceramic restorations. Dent. Mat 2013; 29: 339-347.

12. Shillingburg HT, Hobo S, Whitsett LD, Jacobi R, Brackett SE. Fundamentals of fixed prosthodontics. Tokyo: Quintessence; 2007.

13. Tiu J, Al-Amleh B, Waddell JN, Duncan WJ. Clinical tooth preparations and associated measuring methods: A systematic review. J Prosthet Dent 2015; 113:175-184.

14. Arora A, Upadhyaya V, Arora SJ, Sangwan R. Evaluation of the effectiveness of auxiliary features on resistance with decreased occluso-cervical height: An in vitro study. Indian J Dent Sci 2016; 8:139-144.

15. Egbert JS, Johnson AC, Tantbirojn D, Versluis A, Cam $\mathrm{CAD}$. Fracture strength of ultrathin occlusal veneer restorations made from CAD / CAM composite or hybrid ceramic materials. Oral Sci Int. 2015; 86:8-13.

16. Magne P, Schlichting LH, Maia HP and Baratieri LN. In vitro fatigue resistance of $\mathrm{CAD} / \mathrm{CAM}$ composite resin and ceramic posterior occlusal veneers J Prosthet Dent 2010; 104:149-157.

17. Schlichting LH, Maia HP, Baratieri LN, Magne P. Noveldesign ultra-thin CAD/CAM composite resin and ceramic occlusal veneers for the treatment of severe dental erosion. J Prosthet Dent 2011; 105:217-226.

18. Reich, S. and O. Schierz, Chair-side generated posterior lithium disilicate crowns after 4 years. 2013Clin. Oral. Investig., 17: 1765-1772.

19. Chandra Shekar S, Giridhar K, Suhas Rao K. An in vitro study to evaluate the retention of complete crowns prepared with five different tapers and luted with two different cements. J Indian Prosthodont Soc. 2010; 10:89-95.

20. Johnson AC, Versluis A, Tantbirojn D, et al. Fracture strength of CAD/CAM composite and composite-ceramic occlusal veneers. J Prosthodont Res 2014; 58:107-114.

21. Devigus A, Lombardi G. Shading Vita In-ceram YZ substructures: influence on value and chroma, part II. Int J Comput Dent 2004; 7:379- 388 .

22. Mathew C, Ks S. A review on ceramic laminate veneers. J Indian Acad Dent Spec. 2010;1(4):33-7.

23. Paravina RD, Ontiveros JC, Powers JM. Accelerated aging effects on color and translucency of bleaching-shade composites. J Esthet Restor Dent. 2004;16(2):117-26; discussion 126-7.

24. Chaiyabutr Y, Kois JC, LeBeau D, Nunokawa G. Effect of abutment tooth color, cement color, and ceramic thickness on the resulting optical color of a CAD/CAM glass-ceramic lithium disilicate-reinforced crown. J Prosthet Dent. 2011;105(2):83-90

25. Alghazali N, Burnside G, Moallem M, Smith P, Preston A, Jarad FD. Assessment of perceptibility and acceptability of color difference of denture teeth. J Dent. Elsevier; 2012; 40:10-7.

26. Renata B R, Erick L, Marina G R, Carlos J S, Paulo F C, Veridiana R N. Influence of Resin Cements on Color Stability of Different Ceramic Systems 2017 Braz Dent J 28(2): 191-195

27. Yilmaz B, Karaagaclioglu L. In vitro evaluation of color replication of metal ceramic specimens using visual and instrumental color determinations. J Prosthet Dent 2011; 105:21-7

28. Ledi_c K, Majnari_c I, Milardovi_c S, Ortolan SM, SSpalj S, _Stefan_ci_c S, et al. Analysis of translucency parameter of glass-ceramics fabricated by different techniques. Acta Stomatol Croat 2015; 49:27-35. 
29. Vichi A, Carrabba M, Paravina R, Ferrari M. Translucency of ceramic materials for CEREC CAD/CAM system. J Esthet Restor Dent 2014; 26:224-31.

30. Gloria B A, Guilherme B C, Demarcob T P. The Effect of Luting Agents and Ceramic Thickness on the Color Variation of Different Ceramics against a Chromatic Background. Eur J Dent 2011; 5:245-252

31. Albuquerque PP, Moreira AD, Moraes RR, Cavalcante LM, Schneider LF. Color stability, conversion, water sorp- tion and solubility of dental composites formulated with different photoinitiator systems. J Dent 2013;41: e67-e72.

32. Almeida JR, Schmitt GU, Kaizer MR, Boscato N, Moraes RR. Resin-based luting agents and color stability of bonded ceramic veneers. J Prosthet Dent 2015; 114:272-277.

33. Chen XD, Hong G, Xing WZ, Wang YN. The influence of resin cements on the final color of ceramic veneers. J Prosthodont Res 2015; 59:172-177. 